\title{
Microphysical examination of excess cloud absorption in the tropical atmosphere
}

\author{
Dan Lubin, ${ }^{1,2}$ Jen-Ping Chen, ${ }^{1,3}$ Peter Pilewskie, ${ }^{4}$ V. Ramanathan, ${ }^{1,2}$ and \\ Francisco P. J. Valero ${ }^{1,5}$
}

\begin{abstract}
To investigate the excess shortwave absorption by clouds, a numerical cloud generation model has been coupled to a plane-parallel discrete ordinates radiative transfer model. The former was used in a time-dependent fashion to generate a cumulonimbus turret and three types of cirrus anvil (precipitating, extended, detached) representing three stages of cloud evolution outward from the turret. The cloud particle size distributions, as a function of altitude, were used as input to the radiative transfer model using indices of refraction for pure water and pure ice and equivalent sphere Mie theory. The radiative transfer model was used to calculate the ratio of cloud forcing at the surface to cloud forcing at the top of the atmosphere, both for the broadband shortwave and as a function of wavelength. Recent empirical studies have placed this cloud forcing ratio at around 1.5, and our coupled model results approach this value for small solar zenith angles, when the cloud contains large $(>100 \mu \mathrm{m})$ ice particles that absorb significantly in the near infrared (primarily the 1.6- $\mu \mathrm{m}$ window). However, the empirical studies are based on diurnal averages, and our plane-parallel radiative transfer model yields an area and diurnally averaged cloud forcing ratio of only 1.18 for a tropical cumulonimbus and cirrus anvil system, primarily because of the rapid decrease of the ratio with solar zenith angle. The ratio decreases because of the increase in albedo with solar zenith angle, which is a characteristic feature of plane-parallel clouds. Adding dust or aerosol to the cloud layers, to make them absorb at visible wavelengths, makes the instantaneous cloud forcing ratio larger for an overhead Sun but also makes the solar zenith angle dependence in the cloud forcing ratio more pronounced. These two effects cancel, eliminating interstitial aerosol as a possible explanation for the excess cloud absorption in plane-parallel radiative transfer modeling. The strong dependence of the surface/top of the atmosphere cloud forcing ratio on solar zenith angle may be a fundamental defect with the plane-parallel approach to solar radiative transfer in a cloudy atmosphere.
\end{abstract}

\section{Introduction}

The topic of absorption of solar radiation in clouds has been the subject of intense investigation over the last several decades [Stephens and Tsay, 1990; Liou, 1992]. Threc recent studies provide compelling evidence that the present generation of general circulation models (GCMs) underestimates the absorption of solar radiation by clouds by an average of $25 \mathrm{~W}$ $\mathrm{m}^{-2}$ [Cess et al., 1995; Pilewskie and Valero, 1995; Ramanathan et al., 1995]. For a 50\% fractional cloud cover, this implies that the overcast regions absorb about $50 \mathrm{~W} \mathrm{~m}^{-2}$ more compared to the surrounding clear skies. These studies used satellite, airbornc, and ground-based radiometry to detcrminc the shortwave cloud radiative forcing (defined as the difference in

${ }^{1}$ Center for Atmospheric Sciences, Scripps Institution of Oceanography, University of California, San Diego.

${ }^{2}$ Also with California Space Institute, University of California, San Diego.

${ }^{3}$ Now at Department of Atmospheric Sciences, National Taiwan University, Taipei.

${ }^{4}$ NASA Ames Research Center, Moffett Field, California.

${ }^{5}$ Atmospheric Research Laboratory, Scripps Institution of Oceanography, University of California, San Diego, La Jolla.

Copyright 1996 by the American Geophysical Union.

Paper number 96JD01154.

0148-0227/96/96JD-01154\$09.00 net shortwave flux between cloudy and equivalent clear atmospheres) at the top of the atmosphere, $C_{s t}$, and at the surface, $C_{s s}$, and have shown that the latter is generally 1.5 times greater than the former. The fact that current GCMs calculate $C_{s t} \approx C_{s s}$, thus specifying far less absorption by clouds, indicates a significant gap in our understanding of solar radiation transport in the real atmosphere. A fourth study confirms that $C_{s s} / C_{s t} \approx 1.5$ in the tropics but disputes it at other latitudes [Li et al., 1995]. However, the near-global consistency of the large cloud forcing ratio in the first three studies somewhat rules out explanations by regionally dependent phenomena, such as boundary layer aerosol [e.g., Kiehl and Briegleb, 1993], and motivates us to cxaminc the fundamentals of solar absorption by atmospheric moisture in the liquid and solid phases. We carried out the present investigation for the atmosphere in the western tropical Pacific, which we have recently characterized by comprehensive field measurements as part of the Tropical Ocean Global Atmosphere Coupled Ocean-Atmosphere Response Expcriment [TOGA-COARE; Webster and Lukas, 1992] and the Central Equatorial Pacific Experiment [McFarquhar and Heymsfield, 1996; Lubin, 1994].

The advance of this study over previous radiative transfer studies lies in the use of detailed cloud microphysics in which cloud particle size distribution and water content, for both ice and liquid water, is specified as a function of altitude by numerical simulation. A one-dimensional, time-dependent model 
(A) CUMULONIMBUS - ICE

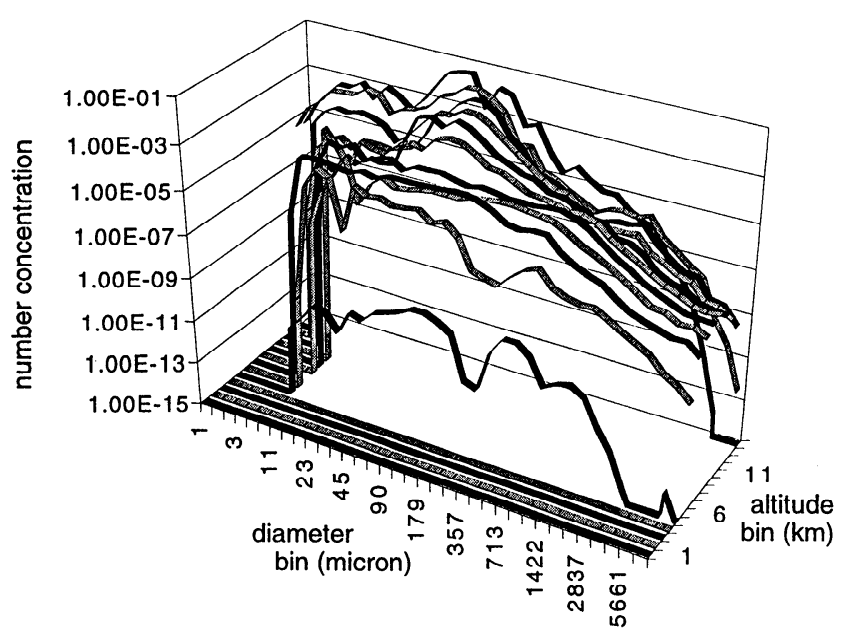

Figure 1. (a-e) Number concentrations $\left(\mathrm{cm}^{-3} \mu \mathrm{m}^{-1}\right)$ for ice particles in the four cloud types generated by the microphysical model, as a function of particle diameter and altitude (cumulonimbus (CB)) or temperature (cirrus cases). The liquid water drop number concentration is also shown for the CB. Diameter bins are identified by the midpoint of the bin. In the CB plots, there are 15 altitude bins between 1 and $15 \mathrm{~km}$ each identified by the upper bound. In the cirrus plots, there are 7 temperature ranges of width $10^{\circ} \mathrm{C}$, each identified by the upper bound. Note the altitude axis reversal between the $\mathrm{CB}$ ice and the water plots.

similar to that of Wisner et al. [1972] was used to simulate tropical deep convection and cumulonimbus (CB) generation. The outflow portion of this model was then used to drive a time-dependent microphysical simulation within a cirrus anvil, based on the multicomponent model of Chen and Lamb [1994]. Liquid phase microphysical processes included are the activation of cloud condensation nucleii, condensational growth, coalescence, and breakup. Following Whitby [1978], the trimodal distribution of condensation nucleii for a marine surface background atmosphere is used for the model input, with a total number concentration of approximately $400 \mathrm{~cm}^{-3}$. Ice phase processes included are heterogeneous deposition nucleation, heterogeneous freezing, contact freezing, homogeneous freezing, diffusional growth, riming, rime splintering, and aggregation. In this time-dependent simulation the anvil was allowed to persist for 12 hours beyond the development of the cumulonimbus. Three time periods were selected from this simulation and taken to represent typical microphysics of the anvil at varying distance from the generating cumulonimbus. The average of microphysical results after 1 and 2 hours is referred to as "precipitating anvil" (PA), the average after 4 to 6 hours as "extended anvil" (EA), and the average after 10 to 12 hours as "detached anvil" (DA).

The simulations are illustrated in Figures 1a-1e. The CB turret is characterized by ice particles that are relatively small at the top but become progressively larger toward the base. Liquid water droplets in the CB turret are large throughout the cloud but largest in the middle layers (3-8 $\mathrm{km}$ altitude). The PA cirrus cloud exhibits a broad distribution in ice cloud particles at the colder temperatures (cloud top), which is biased toward particles smaller than $100 \mu \mathrm{m}$. As one would expect, the larger precipitation size particles are found settling toward
(B) CUMULONIMBUS - LIQUID

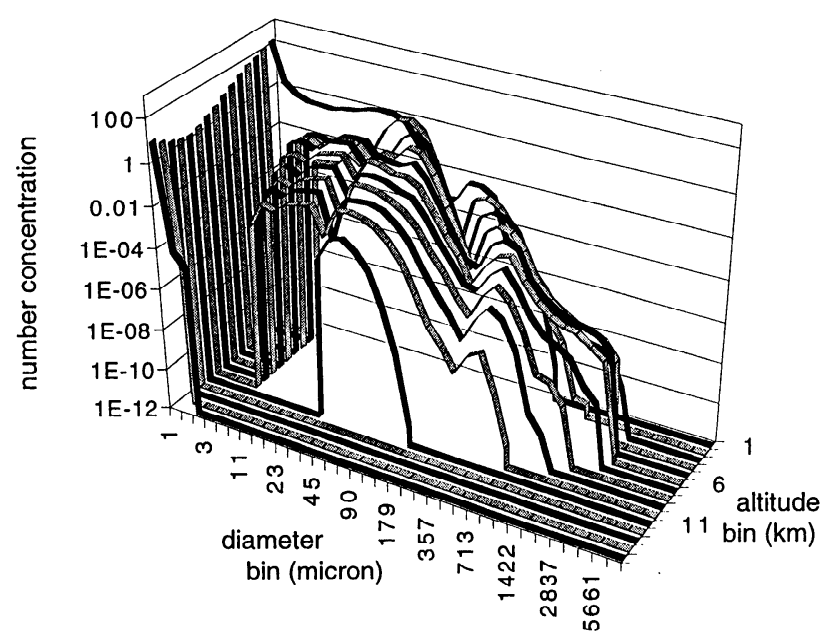

Figure 1. (continued)

the warmer temperatures (cloud base). Ice particles in the EA cirrus cloud are generally an order of magnitude smaller than in the PA, but the EA still exhibits a particle settling effect, with larger size distributions toward the warmer temperatures. The DA cirrus cloud has ice particles that are smaller still and a less pronounced gradient in size distribution from top to bottom.

The altitude-dependent size distribution spectra, for both liquid water and ice particles, were used as input for Mie scattering calculations [Wiscombe, 1980] that determined single-scatter albedo, scattering asymmetry factor, and volume extinction coefficient as a function of wavelength throughout the shortwave. These radiative transfer parameters were then incorporated into a discrete-ordinates radiative transfer simulation [Stamnes et al., 1988]. The phase functions of large ice particles will generally be quantitatively different than those of pure Mie theory; however, both Mie phase functions and actual ice particle phase functions [e.g., Liou, 1992] are both strongly forward peaked, and Mie phase functions are adequate for the treatment of fluxes in a multiple-scattering atmosphere (although not necessarily adcquate for the treatment of radiances). The radiative transfer simulation utilized a model tropical atmosphere compiled from CEPEX radiosonde data and included gaseous absorption (water vapor, $\mathrm{CO}_{2}, \mathrm{O}_{3}$ ) as modeled by the method of exponential sum fitting of transmissions [Wiscombe and Evans, 1977]. Tables of exponential sum fitting weights and coefficients, at $20-100 \mathrm{~cm}^{-1}$ resolution in the near infrared and $100-1000 \mathrm{~cm}^{-1}$ resolution in the visible and ultraviolet, were kindly supplied by S.-C. Tsay (NASA Goddard Space Flight Center, personal communication). A total of 179 spectral bands were used to resolve the solar spectrum from 0.28 to $4.0 \mu \mathrm{m}$. The radiative transfer model was used to calculate the cloud forcing ratio as a function of wavelength, $C_{s s}(\lambda) / C_{s t}(\lambda)$, and the cloud forcing ratio $f_{s}=C_{s s} / C_{s t}$ derived from integrated shortwave net fluxes.

\section{Physical Interpretation of the Cloud Forcing Ratio}

The cloud forcing ratio, $f_{s}$, can be expressed as

$$
f_{s}=\frac{C_{s s}}{C_{s t}}=1+\frac{\bar{A}-A_{c}}{\bar{a}-a_{c}}
$$


(C) PRECIPITATING ANVIL - ICE

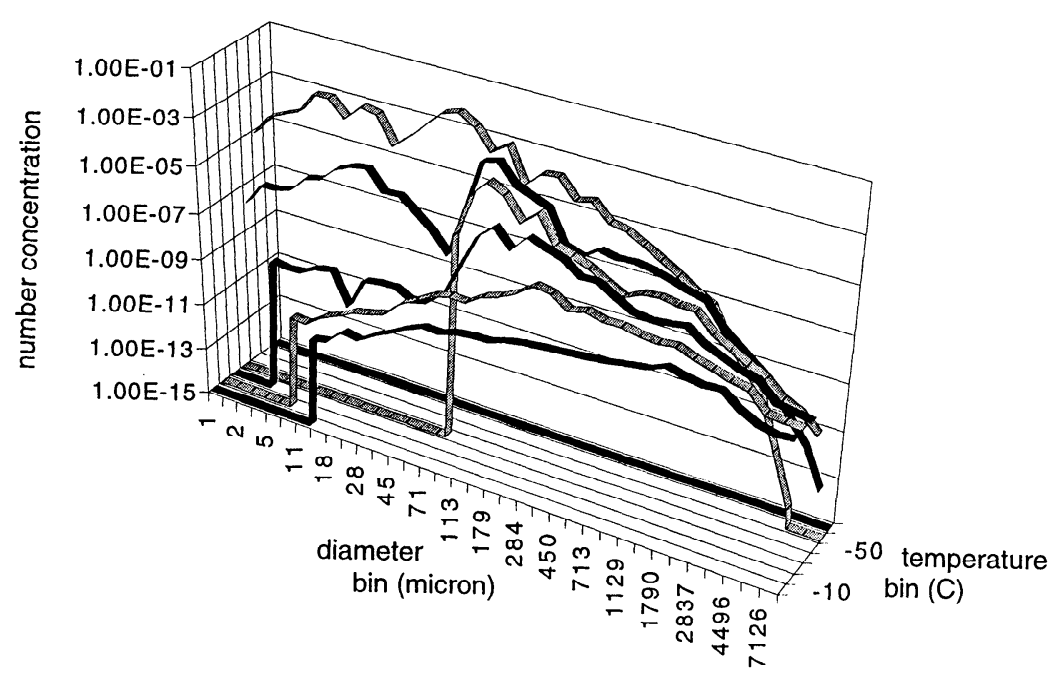

(D) EXTENDED ANVIL - ICE

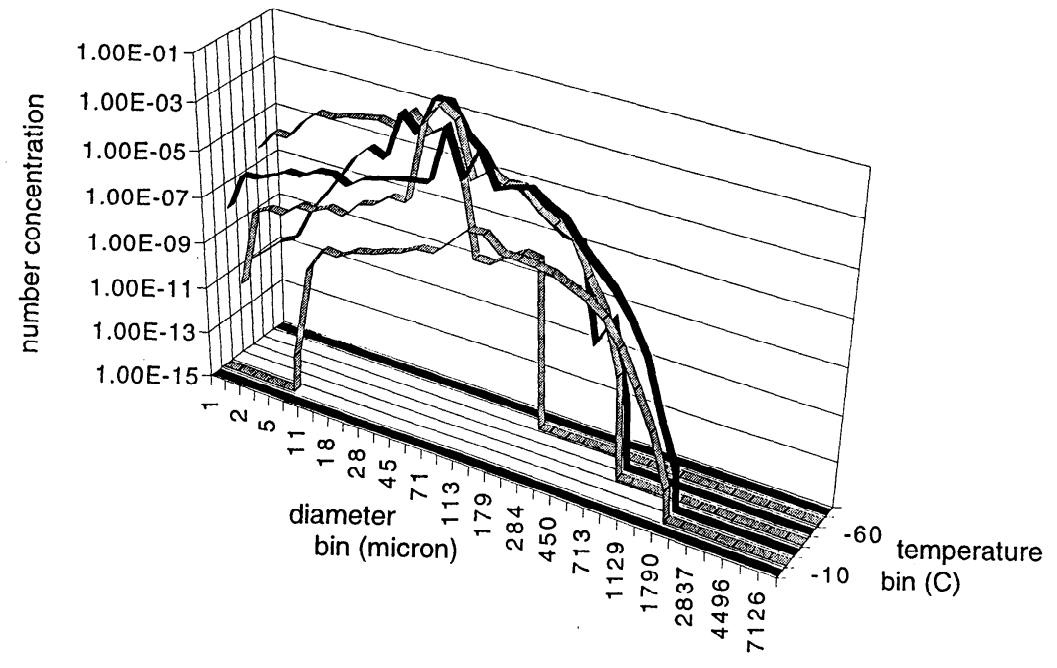

(E) DETACHED ANVIL - ICE

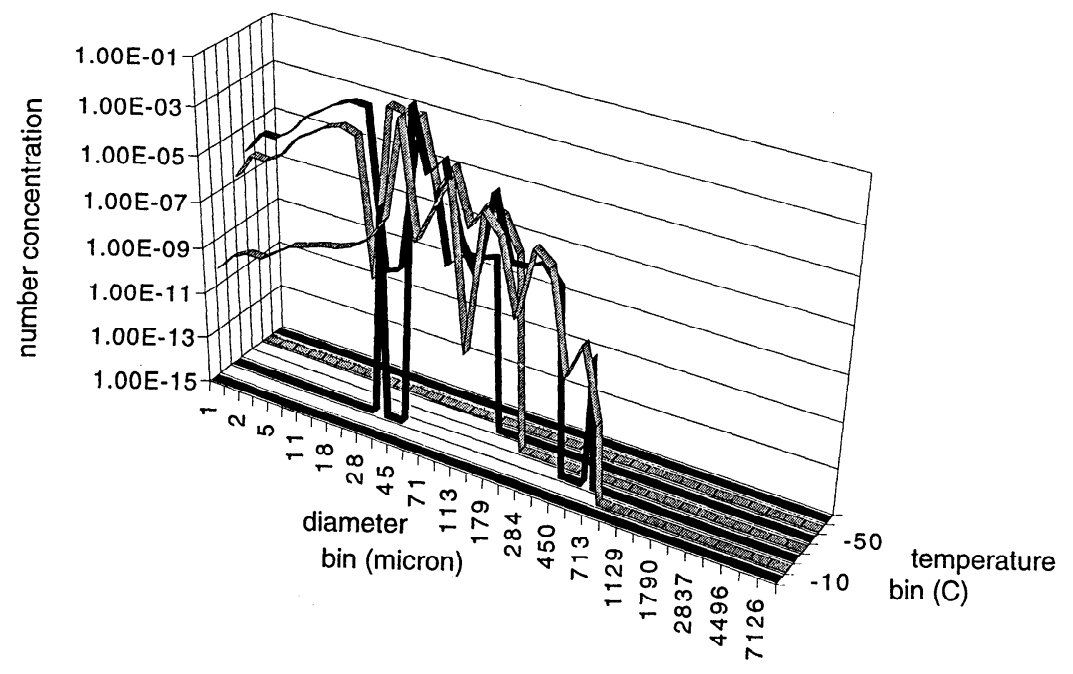

Figure 1. (continued) 

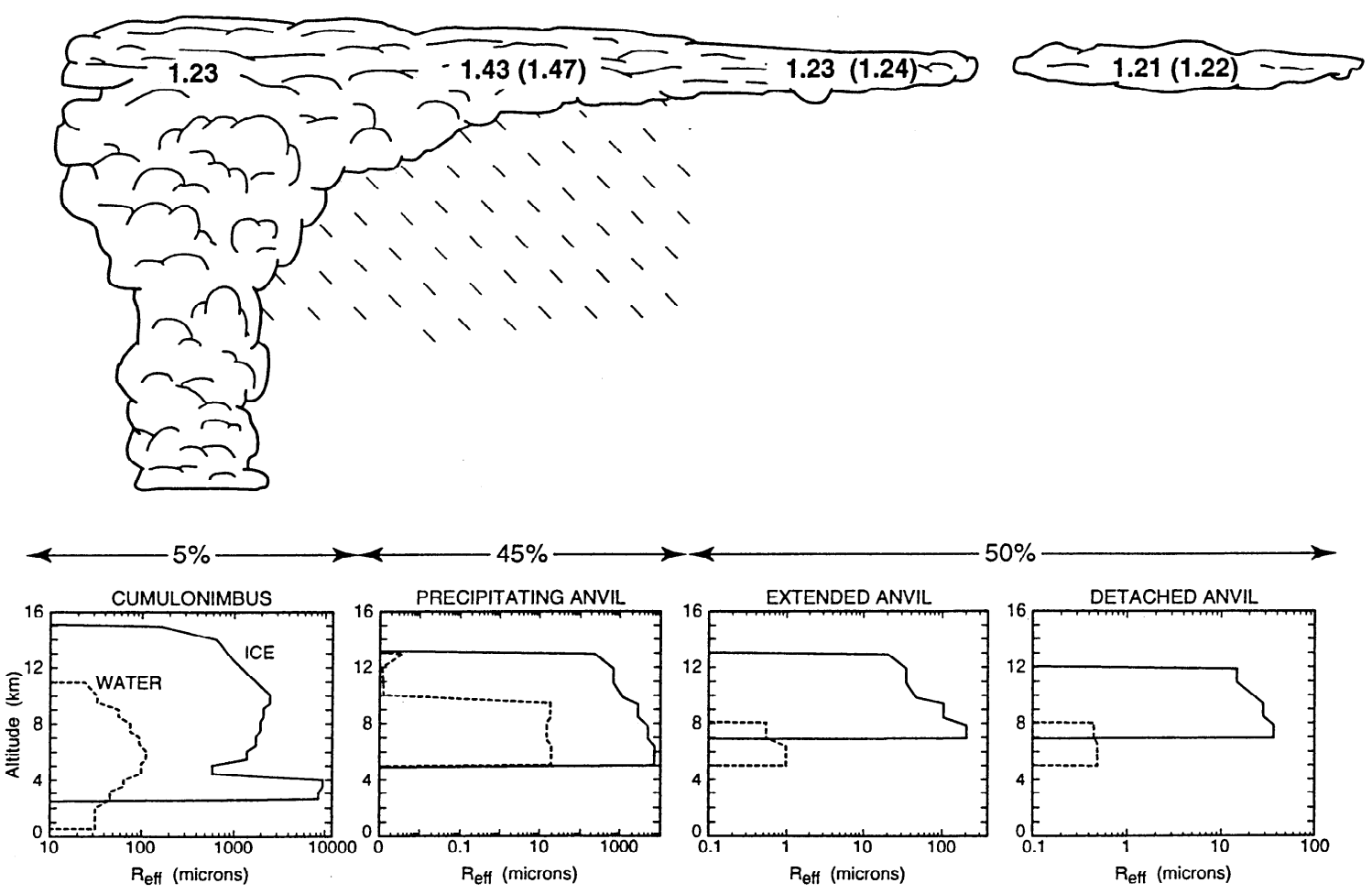

Figure 2. Effective radius of the liquid water and ice particle size distributions as a function of altitude, for the four tropical cloud types considered. Percentages given above the plots represent the area coverage of the cloud types in a typical tropical deep convective system, as inferred from GMS data. The cloud forcing ratios $\int_{s}$ are given in the sketch for a solar zenith angle of $10^{\circ}$. Ratios in parentheses pertain to cirrus clouds without liquid water. The visible wavelength optical depths for ice (liquid water) are $4.4(50.5), 3.2(0.3), 3.3(0.3), 3.3$ $(0.1)$, for the $\mathrm{CB}$, precipitating anvil (PA), extended anvil (EA), and detached anvil (DA), respectively.

where $A$ is the vertically integrated solar absorption within the atmospheric column normalized by the top of the atmosphere (TOA) solar irradiance; and $a$ is the planetary albedo at the top of the atmosphere. The subscript $c$ refers to clear skies and the overbar refers to average cloudy conditions. For a cloudy atmosphere, with cloud fraction $C$, the avcragc albcdo is defined as

$$
\begin{aligned}
& \bar{a}=a_{c}(1-C)+a_{o} C \\
& \bar{A}=A_{c}(1-C)+A_{o} C
\end{aligned}
$$

where $a_{0}$ and $A_{0}$ are, respectively, the albedo and the atmospheric absorption for overcast skies. Upon inserting (2a) and $(2 b)$ in (1), we obtain an alternate equation for $f_{s}$ :

$$
f_{s}=\frac{C_{s s}}{C_{s t}}=1+\frac{A_{o} A_{c}}{a_{o}-a_{c}}
$$

The physical significance of $f_{s}$ is obvious from (3). If the cloudy atmospheric column absorption $\left(A_{o}\right)$ is same as that of clear sky $\left(A_{c}\right)$, then $f_{s}=1$; if it exceeds $A_{c}$, then $f_{s}>1$. Thus $f_{s}$ is a measure for the effect of clouds on atmospheric absorption. Our current understanding of this fundamental parametcr is largely based on models. The Cess et al. [1995] study is the first observational attempt to estimate this parameter from satellite data and suggests that $f_{s} \approx 1.49$. The Pilewskie and Valero [1995] study is the first attempt to measure this parameter in situ using airborne radiometers and suggests that $f_{s} \approx$ 1.58 in the tropics, whereas models indicate $f_{s} \approx 1$. It is misleading to denote this difference as "anomalous absorp- tion." It is anomalous when compared with models but not otherwise; the fact is that its true value is unknown.

The ratio $f_{s}$ is needed for a particular local time as well as for diurnally average conditions. For a local time, $C_{s s}$ and $C_{s t}$ have to be averaged first for all of the cloud types within a region and the ratio should be obtained from these averaged values of $C_{s s}$ and $C_{s t}$. For diurnal average conditions, $f_{s}$ is the ratio of the diurnal average values of $C_{s s}$ (averaged over all cloud types) and $C_{s t}$ (averaged over all cloud types).

\section{Integrated Shortwave Results}

The ratio $f_{s}$ was found to depend strongly on the microphysics (Figure 2). Values of $f_{s}$ are largest for ice particle size distributions containing the largest particles (precipitating anvil), due to more efficient absorption of solar near-infrared radiation. The addition of water droplets, much smaller in effective radius than the ice particles, reduces $f_{s}$ very slightly by adding to the cloud optical depth (and hence albedo) while not adding much to the near-infrared absorption. For a similar reason the ratio $f_{s}$ was also found to depend very much on solar elevation, being greater than unity for all four cloud types under an overhead Sun, decreasing to unity or smaller with the Sun nearly on the horizon. This solar zenith angle dependence has been observed by aircraft radiometers [Pilewskie and Valero, 1995]. If the direct solar beam strikes the cloud top at a large angle of incidence, scattering in the uppermost layers of the cloud becomes more important relative to the lower layers, and thus relatively more near-infrared radiation can escape to 
space. Hence for a decreasing Sun elevation the cloud albedo increases at the expense of $f_{s}$. The diurnally averaged ratio $f_{s}$ is therefore smaller than the ratio at high Sun elevation. Figure 2 gives the ratios $f_{s}$ for a solar zenith angle of $10^{\circ}$. The diurnally average $f_{s}$ would depend on the diurnal variation of cloud types and cloud cover. If we make the unrealistic assumption that cloud types and cloud amounts are independent of local time, the diurnally averaged values of $\left\langle f_{s}\right\rangle\left\{=\left\langle C_{s s}\right\rangle /\left\langle C_{s t}\right\rangle\right\}$ are $1.18,1.26,1.12$, and 1.10 for the $\mathrm{CB}, \mathrm{PA}, \mathrm{EA}$, and DA, respectively.

The simulated ice particle effective radii of the $\mathrm{CB}$ and PA in Figure 1 are very large at all altitudes. Figure 1 shows that for most altitudes the number concentrations of the largest (millimeter size) particles are several orders below the maxima of the distributions, but as the effective radius is defined as

$$
r_{c}(z)=\frac{\int r^{3} n(r, z) d r}{\int r^{2} n(r, z) d r^{\prime}}
$$

where $r$ is the particle radius and $n(r, z)$ is the particle size distribution $\left(\mathrm{cm}^{-3} \mu \mathrm{m}^{-1}\right)$, the largest particles contribute greatly to the value of $r_{c}(z)$. McFarquhar and Heymsfield [1996] report measurements of millimeter-sized cirrus anvil ice particles in the $-31^{\circ} \mathrm{C}$ temperature range during $\mathrm{CEPEX}$, but other experimental determinations of $r_{e}$ for tropical cirrus clouds are generally much smaller than those we use for the PA in this study [e.g., Knollenberg et al., 1993]. The particle size discrepancy between our PA simulations and many earlier studies could mean one of two things. First, because in situ measurements require aircraft, which will not fly into dangerous convective conditions, it may be the case that the interior of a true precipitating anvil has never really been sampled (and certainly the interior of a towering cumulonimbus turret is near impossible to sample with a research aircraft). For example, the observations of Knollenberg et al. [1993] apply only to the cloud tops. Second, it could be the case that our microphysical simulations indeed overestimate the ice particle size in the PA. If the latter is true, then this study can be considered an absolute upper bound to the applicability of large particles as an explanation for cloud excess absorption. In this study we show that the solar zenith angle dependence in the planetary albedo renders a plane parallel model incapable of reproducing the diurnally averaged cloud absorption noted in recent studies, even for ice particles that may be larger than occur in nature.

Geostationary Meteorological Satellite (GMS) infrared images were used to estimate the relative contribution of the various cloud types to the total cloud cover over the western tropical Pacific. We used one month of GMS data having a pixel resolution of $5 \times 5 \mathrm{~km}$. First, we found that the upper tropospheric clouds, including the convective cloud system, contributed about $85 \%$ to the total cloud albedo. Thus the cumulonimbus plus precipitating anvils and extended cirrus modeled here are the dominant contributors to the total cloud albedo. Second, the cumulonimbus plus precipitating anvils constitute approximatcly $50 \%$ of the total upper tropospheric fraction with the balance from extended and detached cirrus (Figure 1). The cloud types are identified on the basis of satellite 10 - to $12-\mu \mathrm{m}$ window brightness temperatures, $T_{B} . T_{B}$ $<219 \mathrm{~K}$ is cumulonimbus; $219<T_{B}<240$ is defined as precipitating anvils; $T_{B}>240$, but attached to a precipitating anvil is extended cirrus; $240<T_{B}<260$ is detached anvil. There is a significant uncertainty in identifying cloud types based solely on satellite data; hence we should treat the relative cloud fractions shown in Figure 2 as rough cstimates subject to at least $25 \%$ (relative) error. Besides, these relative fractions may change diurnally, which are also ignored in this study. Nevertheless, the values adopted here should be sufficient to articulate the main points of this study.

There is rough correspondence between these satellitederived cloud types and those obtained from the microphysical model. By correlating satellite $T_{B}$ with radar-derived precipitation, it has been established [Laing and Fritsch, 1993] that active regions of deep convection are those with IR temperaturcs less than about $219 \mathrm{~K}$ and that precipitating anvils have IR temperatures colder than $240 \mathrm{~K}$. In the cloud model, the microphysics of the deep updraft is associated with the cumulonimbus, which, in principle, should be the active regions of convection, i.e., $T_{B} \leq 219 \mathrm{~K}$. Since precipitation was sustained for about 2 hours in the microphysical model, this time period was assumed to correspond to the precipitating anvil $\left(T_{B}<\right.$. $240 \mathrm{~K}$ ) clouds; to be consistent with the microphysical model, in the satellite data we associate only those pixels which are attached to a convective core $\left(T_{B}<219 \mathrm{~K}\right)$ as the precipitating anvils.

Taking into account the respective cloud fractions, the overall diurnally averaged cloud forcing ratio may be estimated as

$$
\left\langle f_{s}\right\rangle=\frac{\sum_{i=1}^{4} a_{i} F_{s s, i}^{(c)}-F_{s s}^{(\mathrm{clr})}}{\sum_{i=1}^{4} a_{i} F_{s t, i}^{(c)}-F_{s t}^{(\mathrm{clr})}}
$$

where $F_{s s, i}^{(c)}$ and $F_{s t, i}^{(c)}$ are the diurnally averaged cloudy sky net fluxes at the surface and top of the atmosphere, respectively, for each of the four cloud types. The area fraction of the total cloud cover containing cloud type $i$ is given by $a_{i} . F_{s s}^{(\mathrm{clr})}$ and $F_{s t}^{(\mathrm{clr})}$ are the diurnally averaged clear sky net fluxes at the surface and top of the atmosphere, respectively. Using GMSinferred area fractions of $0.05,0.45,0.25$, and 0.25 for cloud types CB, PA, EA, and DA, respectively, and assuming diurnally invariant cloud types and amounts, we find that $\left\langle f_{s}\right\rangle=$ 1.18 .

Our in situ data from TOGA-COARE and CEPEX support the general behavior in our model results (Figure 3). We collocated radiometer data from a NASA ER-2 overflying an anvil system with similar data from the NASA DC-8 underflying the same anvil system to determine $f_{s}$ as a function of distance from the generating cumulonimbus. Because these fluxes were measured in close proximity to the clouds [Pilewskie and Valero, 1995] and therefore do not include absorption by the entire atmosphere column, we also calculated the ratio $f_{s}^{*}$ of cloud forcings at 5 and $20 \mathrm{~km}$ instead of the surface and top of atmosphere. The calculated ratio $f_{s}^{*}$ relevant to aircraft measurements is $8-10 \%$ larger than $f_{s}$ but is still smaller than the actual measurements throughout most of the comparison. One noticeable difference between our ice cloud microphysical simulations and the cirrus clouds sampled by Pilewskie and Valero [1995] is that the latter had a base altitude of approximately $10 \mathrm{~km}$, while our simulations have the cloud base extending down to $5 \mathrm{~km}$ (in the precipitating anvil the 


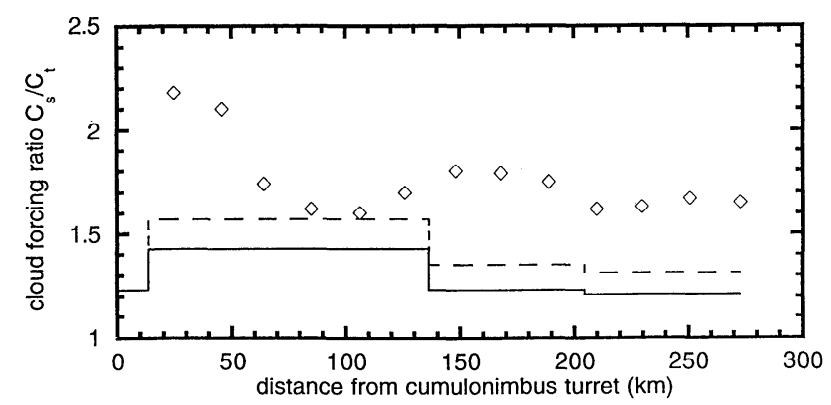

Figure 3. The cloud forcing ratio for tropical cirrus versus distance from a generating cumulonimbus turret. Points are derived from colocated radiometric measurements made during the Central Equatorial Pacific Experiment from an ER-2 (above the cloud) and the NASA DC-8 (below the cloud). The solar zenith angle during this data collection is approximately $24^{\circ}$. The lines depict radiative transfer results, for a solar zenith angle of $10^{\circ}$, transitioning from $\mathrm{CB}$ to PA, EA, and DA (left to right). Solid lines depict the cloud forcing ratio $f_{s}$ based on net fluxes at the surface and top of the atmosphere; dashed lines depict the ratio $f_{s}^{*}$ based on net fluxes at 5 and $20 \mathrm{~km}$ as would apply to colocated aircraft.

largest particles are found between 5 and $6 \mathrm{~km}$, and water droplets extend down to $5 \mathrm{~km}$ in the extended and detached anvils). Because of this discrepancy we also repeated the calculations of Figure 3 for a ratio of cloud forcings at 10 and 20 $\mathrm{km}$. This makes the trace gas absorber column very similar to that sampled by Pilewskie and Valero [1995] but puts the lower altitude inside our simulated clouds. We calculate cloud forcing ratios for 10 and $20 \mathrm{~km}$ of $1.63,1.19$, and 1.02 for the PA, $\mathrm{E} \Lambda$, and DA, respectively. From the ratios $f_{s}^{*}$ it appears that the excess absorption phenomenon cannot be explained entirely by the use of very large ice particles in a plane-parallel radiative transfer model, although large particles may contribute to it.

\section{Spectral Composition}

The relative importance of near-infrared absorption can be ascertained by examining $C_{s s}(\lambda) / C_{s t}(\lambda)$ (Figure 4). For all cloud types, $C_{s s}(\lambda) / C_{s t}(\lambda)$ is essentially unity at wavelengths less than $1.2 \mu \mathrm{m}$. At these wavelengths, cloud scattering is essentially conservative [e.g., Liou, 1992]. The local maxima in $C_{s s}(\lambda) / C_{s t}(\lambda)$ between 0.30 and $0.33 \mu \mathrm{m}$ are due to multiple scattering of ultraviolet radiation in the presence of tropospheric ozone [Frederick and Lubin, 1988]. For the full (both ice and water) PA distribution, $C_{s s}(\lambda) / C_{s t}(\lambda)$ nearly doubles between 1.20 and $1.30 \mu \mathrm{m}$, then reaches 20 in the $1.6-\mu \mathrm{m}$ window and 40 in the $2.2-\mu \mathrm{m}$ window. If the liquid water is excluded from the radiative transfer calculations, $C_{s s}(\lambda) /$ $C_{s t}(\lambda)$ is just slightly larger in all the near-infrared windows. If the full PA distribution is truncated to exclude all particles larger than $20 \mu \mathrm{m}$ in radius, $C_{s s}(\lambda) / C_{s t}(\lambda)$ remains less than 2 out to $2.5 \mu \mathrm{m}$.

The cumulonimbus case exhibits slightly different behavior in $C_{s s}(\lambda) / C_{s t}(\lambda)$ (Figure $4 \mathrm{~b}$ ), although the overall conclusions are the same as for the anvils. Here the cloud optical depth is very large, and while ice particles are an important contributor in tcrms of absorption, most of the total opacity comes from liquid water. This creates a more complicated radiative transfer scenario than that seen in the optically thin anvils. Here we see that even if we truncate the distribution to exclude particles larger than $20 \mu \mathrm{m}$, the optical depth (i.e., abundance of small particles) remains large enough that the cumulative absorption appreciates with large numbers of scattering events. For this truncated distribution, $C_{s s}(\lambda) / C_{s t}(\lambda)$ is of the order of 2 in the 1.6- $\mu \mathrm{m}$ window and approaches 10 in the $2.2-\mu \mathrm{m}$ window. In the 1.6- and $2.2-\mu \mathrm{m}$ windows, $C_{s s}(\lambda) / C_{s t}(\lambda)$ remains essentially unchanged if the liquid water is removed from the full distribution, although the integrated shortwave $C_{s s} / C_{s t}$ increases significantly. This is due to the large decrease in planetary albedo when neglecting the liquid water and to the actual spectral distribution of shortwave radiation, discussed further below. For a given cloud particle size distribution, $C_{s s} / C_{s t}$ was found to increase with decreasing optical depth (liquid or ice water path).

The relative contributions of ice particles and liquid water droplcts to $C_{s s}(\lambda) / C_{s t}(\lambda)$ can bc ascertained by examining the
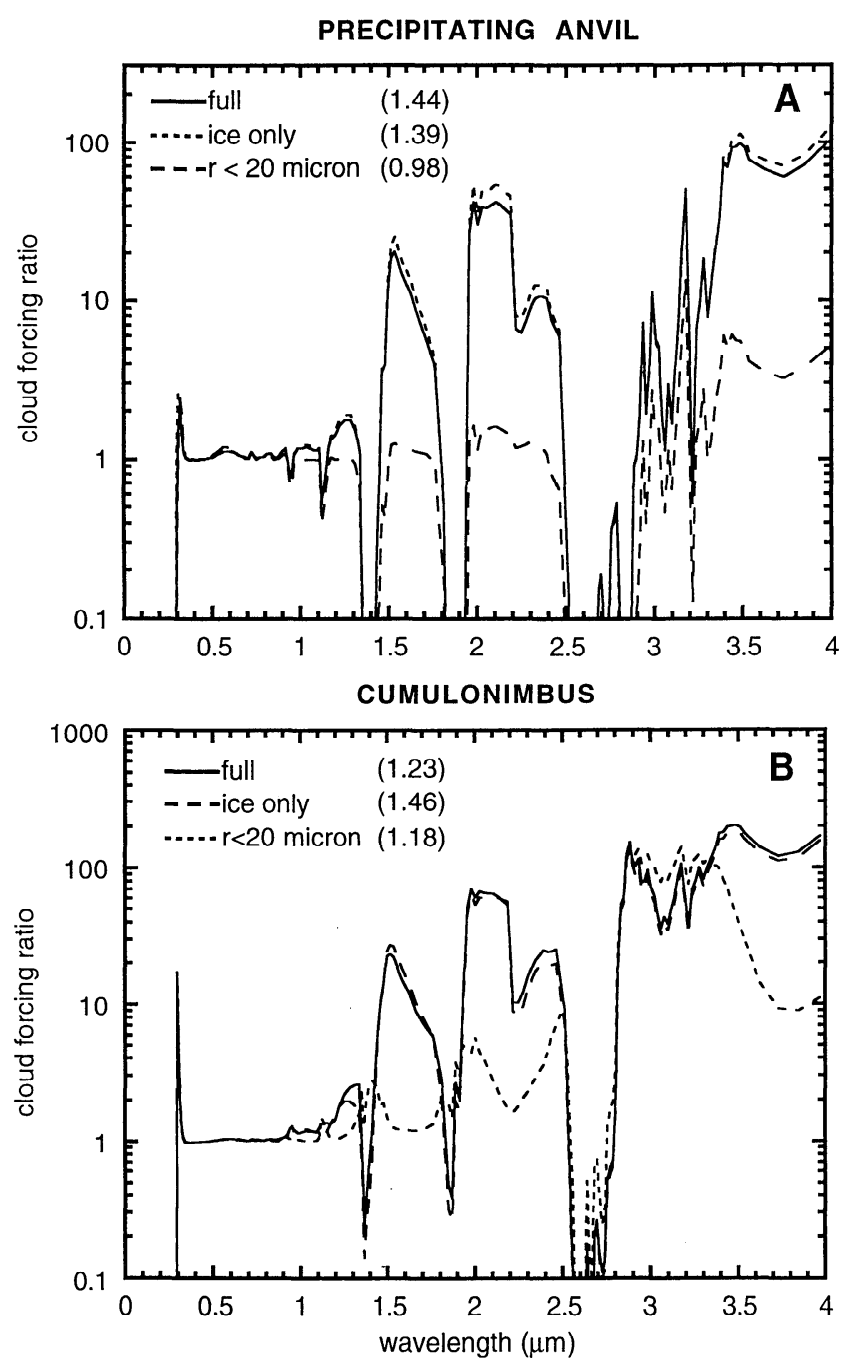

Figure 4. The spectral cloud forcing ratio $C_{s s}(\lambda) / C_{s t}(\lambda)$ for the precipitating anvil (a), and the cumulonimbus (b), under a solar zenith angle of $10^{\circ}$. The solid curve represents radiative transfer results using the full (ice and water) cloud microphysics. The long-dashed curve represents a radiative transfer result using only the ice distributions of Figure 1 . The shortdashed curve represents a radiative transfer result using both ice and liquid water but without particles having a radius greater than $20 \mu \mathrm{m}$. 
planetary albedo as a function of wavelength (Figure 5). In the precipitating anvil case, the liquid water provides $9 \%$ of the volume extinction (optical depth) at visible wavelengths, decreasing to $5 \%$ at $1.6 \mu \mathrm{m}$. The presence of liquid water in the precipitating anvil increases the planetary albedo slightly in the 1.6- and $2.2-\mu \mathrm{m}$ windows, and the resulting backscatter to space leaves less radiation available for absorption by the larger and more absorbant ice particles. This reduces $C_{s s} / C_{s t}$ slightly from 1.47 to 1.43 , for a solar zenith angle of $10^{\circ}$. The influence of ice in the 1.6- $\mu \mathrm{m}$ window is even more apparent in the cumulonimbus case. Here the ice particles contribute only $8 \%$ of the total optical depth at both visible and near-infrared wavelengths. In the visible the planetary albedo barely decreases when ice is removed from the model cloud. However, in the 1.6- $\mu \mathrm{m}$ window the removal of ice from the model cloud causes the planetary albedo to increase by more than a factor of 2. While this cloud is mostly liquid water, the small ice
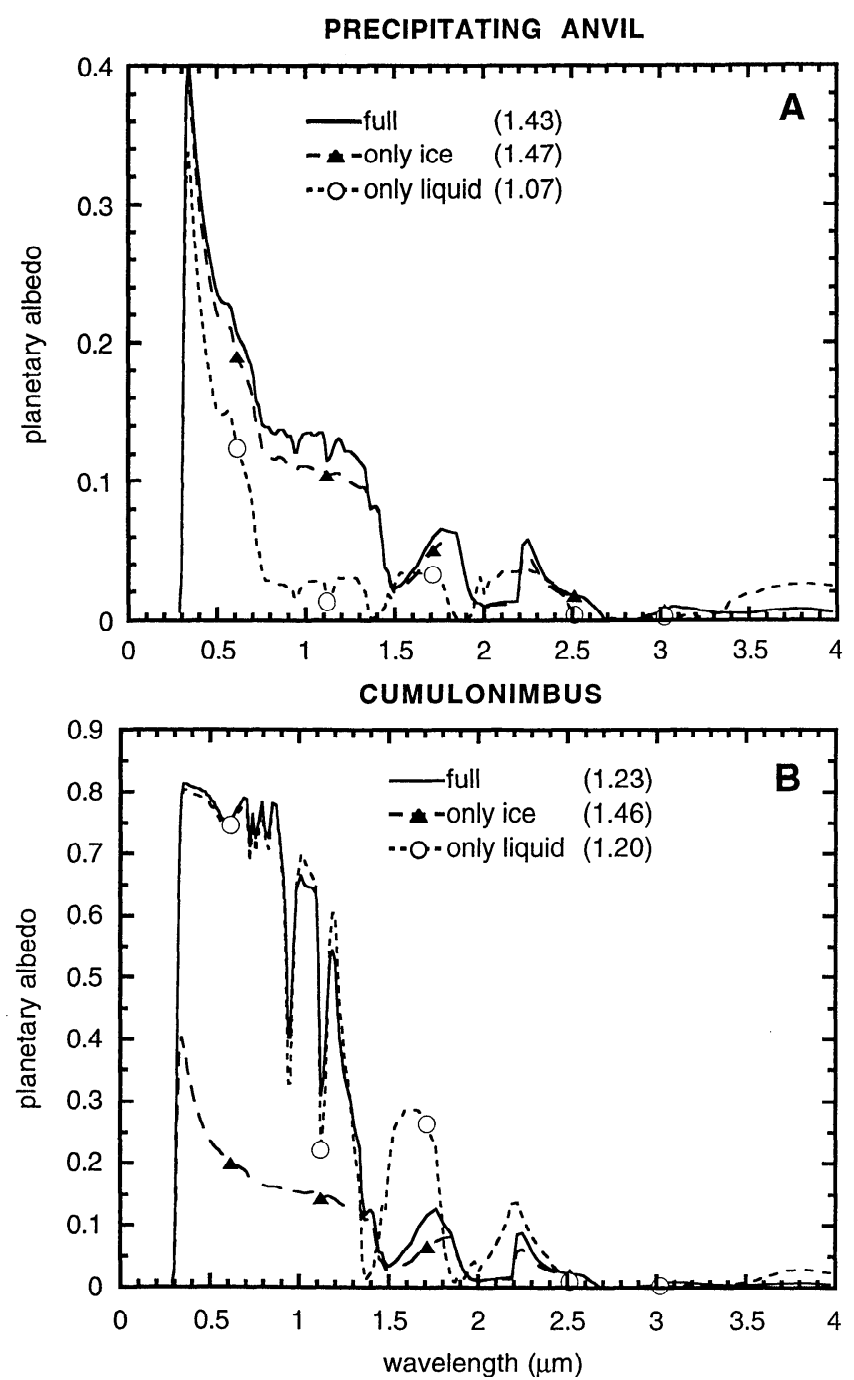

Figure 5. Planetary albedo of a cloudy atmosphere, for the precipitating anvil (a) and the cumulonimbus (b), and a solar zenith angle of $10^{\circ}$. The solid curve represents a radiative transfer result using the full cloud microphysics (ice and water). The long-dashed curve represents a radiative transfer result using only the ice distributions of Figure 1. The shortdashed curve represents a radiative transfer result using only the liquid water distributions of Figure 1.

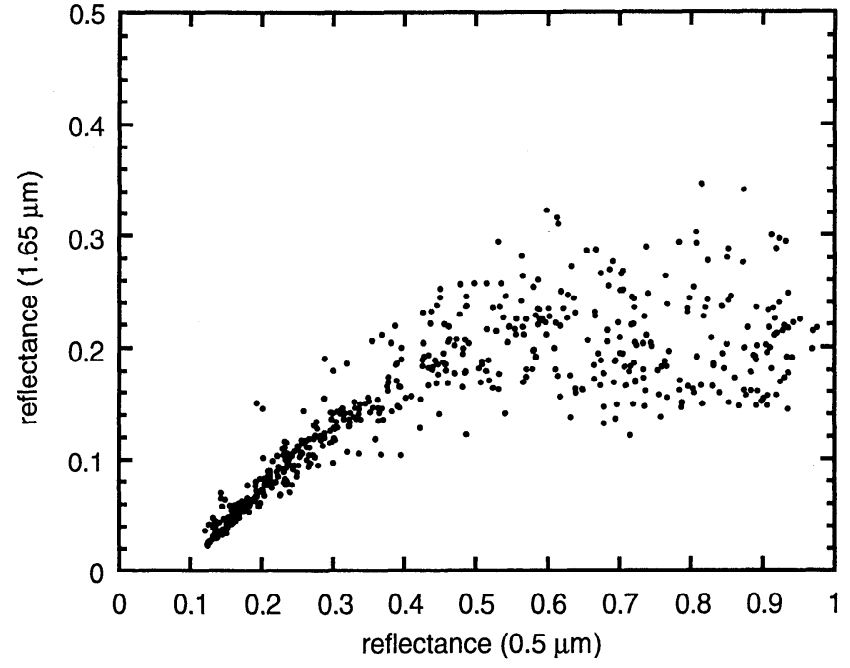

Figure 6. Aircraft radiometer measurements of the tropical cloud reflectance at wavelengths 1.65 and $0.5 \mu \mathrm{m}$. The solar zenith angle is approximately $24^{\circ}$.

opacity dominates the planetary albedo in the 1.6- $\mu \mathrm{m}$ window, which is less than 0.12 for the full (ice plus water) distribution.

The importance of absorption in the 1.6- $\mu \mathrm{m}$ window is seen in aircraft radiometer data from near the tropopause (Figure 6). A multichannel radiometer flown on the NASA ER-2 [Pilewskie and Valero, 1995] allowed us to examine the 1.65- $\mu \mathrm{m}$ cloud top reflectance as a function of $0.5-\mu \mathrm{m}$ cloud top reflcctance, the latter being mostly a conservative scattering effect. Over the ocean the largest $0.5-\mu \mathrm{m}$ cloud top reflectances correspond to optically thicker clouds such as cumulonimbus. For these larger $0.5-\mu \mathrm{m}$ cloud top reflectances, most of the $1.65-\mu \mathrm{m}$ reflectances lie between 0.15 and 0.3 . Optically thin cirrus clouds have smaller $0.5-\mu \mathrm{m}$ cloud top reflectance (Figure $4 \mathrm{a}$ ), and in Figure 5 the smaller $0.5-\mu \mathrm{m}$ reflectances correspond to $1.65-\mu \mathrm{m}$ reflectances rarely larger than 0.15 . These data show that $1.65-\mu \mathrm{m}$ cloud top reflectance rarely exceeds 0.3 for any valuc of the $0.5-\mu \mathrm{m}$ reflectance, thus confirming an important role for cloud absorption in the 1.6- $\mu \mathrm{m}$ window.

Having established the importance of near-infrared absorption by clouds, it remains to be seen if this absorption is at a maximum in the model results considered here. We can determinc this by comparing the difference between the top of the atmosphere insolation and the solar flux backscattered to space, $S(\lambda)$, to the difference between cloud forcings at the top of the atmosphere and the surface, $P(\lambda)$, that is,

$$
\begin{gathered}
S(\lambda)=\mu_{0} F_{0}(\lambda)-F_{s s}(\lambda) \\
P(\lambda)=C_{s t}(\lambda)-C_{s s}(\lambda) .
\end{gathered}
$$

$F_{o}(\lambda)$ is the spectral solar irradiance at the top of the atmosphere, $F_{s s}(\lambda)$ is the backscattered (upwelling) solar flux at the top of the atmosphere, and $\mu_{o}$ is the cosine of the solar zenith angle. $S(\lambda)$ is the solar energy flux absorbed by the oceanatmosphere column. $P(\lambda)$ is the absorption of solar energy flux caused by the presence of cloud scattering particles. Where $P(\lambda) \approx S(\lambda)$, the cloud is responsible for nearly all of the absorption in the Earth-atmosphere column. Where $P(\lambda)<$ $S(\lambda)$, absorption is also due to some other mechanism, primarily molecular attenuation or extinction at the ocean surface. We can also compare these two quantities to the absorp- 
(A) CLEAN PRECIPITATING ANVIL

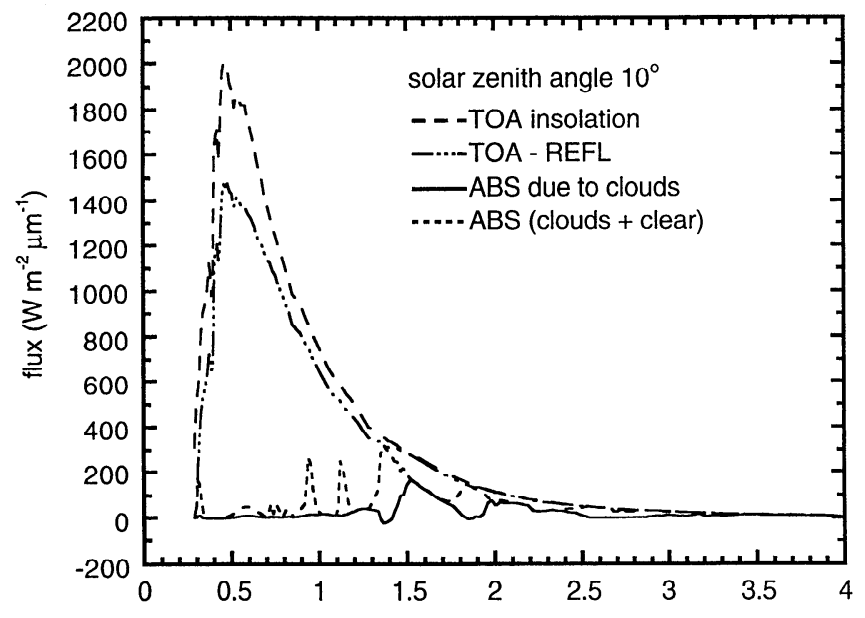

(C) DUSTY PRECIPITATING ANVIL

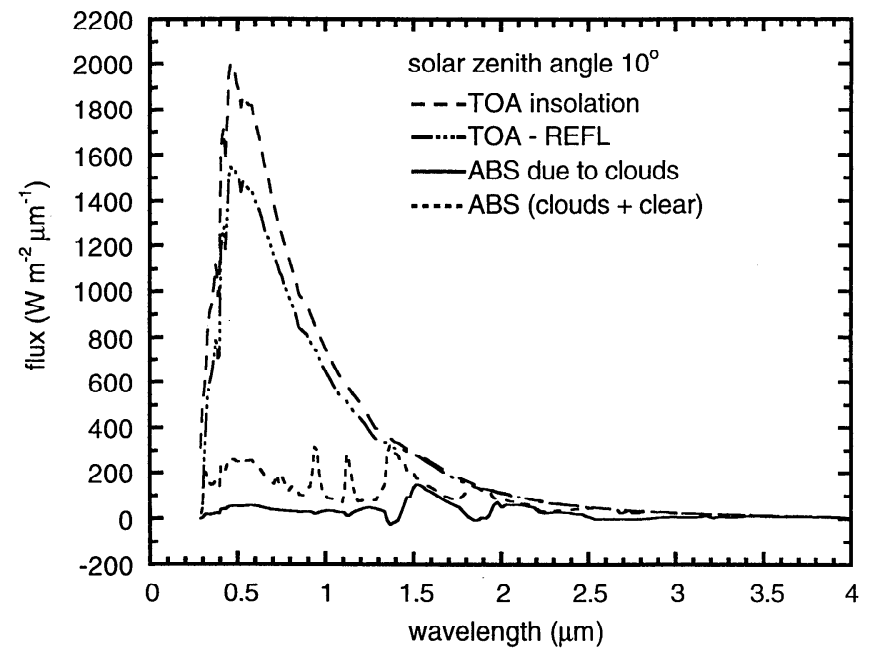

(B) CLEAN CUMULONIMBUS
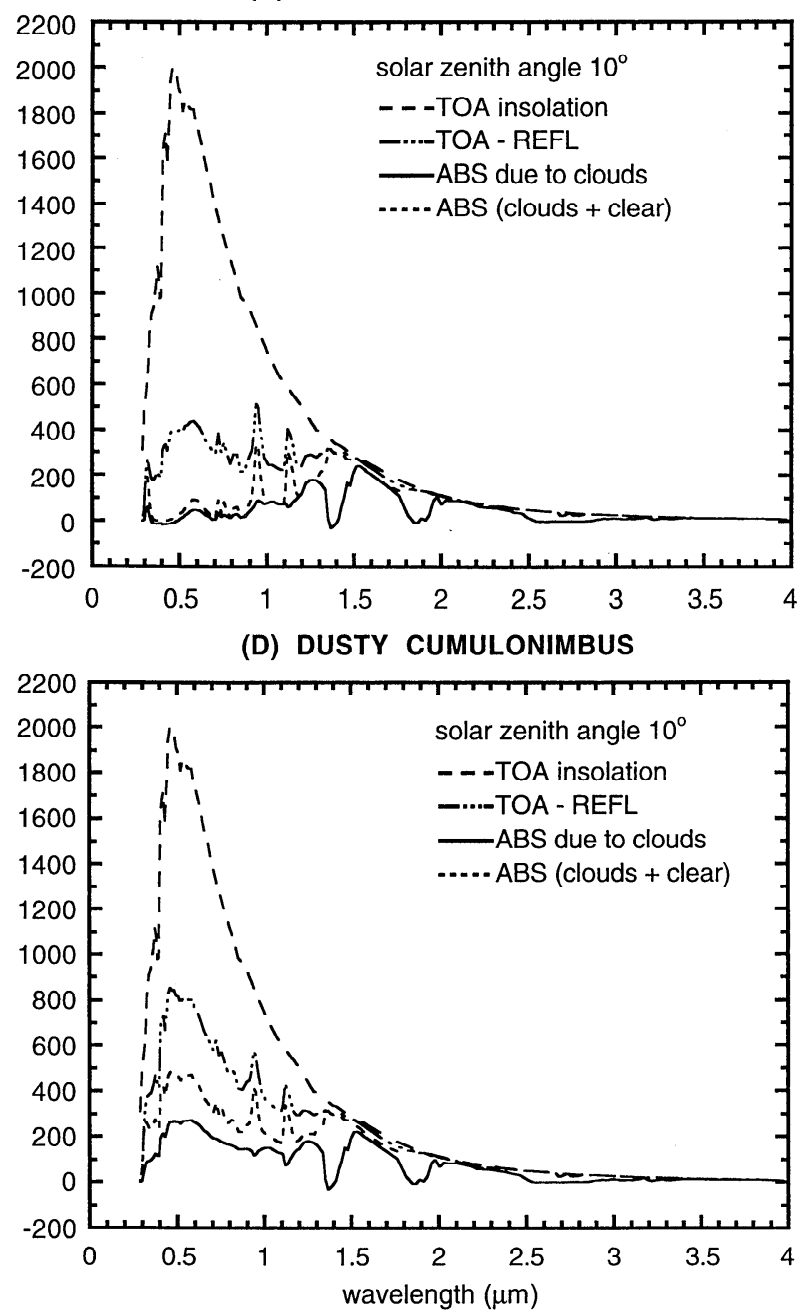

Figure 7. Spectral shortwave absorption and scattering processes in the tropical ocean-atmosphere system, under a solar zenith angle of $10^{\circ}$, for (a) a clean (purc water and ice only) precipitating anvil, (b) a clean cumulonimbus, (c) a dusty precipitating anvil, and (d) a dusty cumulonimbus. The long-dashed curve represents the spectral irradiance at the top of the atmosphere. The dashed-dotted curve represents the quantity $S(\lambda)$. The solid curve represents the quantity $P(\lambda)$. the short-dashed curve represents the quantity $P_{t}(\lambda)$. The cirrus cloud results presented here are for ice-only microphysics.

tion of solar energy flux caused by the presence of both the cloud scattering particles and the molecular extinction,

$$
P_{t}(\lambda)=P(\lambda)+\mu_{0} F_{0}(\lambda)-F_{\mathrm{stc}}^{(u)}-F_{\mathrm{ssc}}^{(\mathrm{net})}(\lambda)
$$

where $F_{\mathrm{stc}}^{(u)}(\lambda)$ is the upwelling flux at the top of the equivalent cloud-free atmosphere, and $F_{\text {ssc }}^{(\text {nct })}(\lambda)$ is the net surface flux under the equivalent cloud-free atmosphere. Where $P(\lambda) \approx$ $P_{t}(\lambda)$, the cloud is responsible for nearly all of the absorption caused by the atmosphere. Where $P(\lambda)<P_{t}(\lambda)$, molecular absorption plays an important role. The contributions of molecular and cloud attenuation effects to the total atmospheric absorption are generally not linear, as the clouds cause multiplc scattcring of radiation within atmospheric layers where molecular absorption also takes place.

$S(\lambda), P(\lambda)$, and $P_{t}(\lambda)$ are shown for the precipitating anvil and cumulonimbus cases in Figures $7 \mathrm{a}$ and $7 \mathrm{~b}$. Absorption by the cirrus cloud is responsible for up to $1 / 2$ of the total column absorption in the 1.6- and 2.2- $\mu \mathrm{m}$ windows. The cumulonimbus exhibits a much larger cloud absorption; in the 1.6- and 2.2- $\mu \mathrm{m}$ windows, $P(\lambda) \approx S(\lambda)$. For the cirrus cloud, $P(\lambda) \approx P_{t}(\lambda)$ in the middle of the 1.6- $\mu \mathrm{m}$ window, while $P(\lambda)<P_{t}(\lambda)$ at both edges. These absorption band edges might be a worthwhile focus for radiometric experiments, to validate our theoretical knowledge of the gaseous absorption efficiency at these wavelengths, as its interaction with cloud scattering affects the ratio $C_{s s}(\lambda) / C_{s t}(\lambda)$ (Figure 4).

Figure 7 also shows a distinction between the absorption effects of cloud in conservative scattering versus nonconservative scattering wavelength regions. In the former (wavelengths less than $1.0 \mu \mathrm{m}$ ) the absorption effect of cloud is due to multiple scattering of photons through trace gases (primarily water vapor and ozone), thus increasing the path length and hence the probability that a photon will be absorbed by the gas. For the cirrus cloud this is very small; integrating $P=\int P(\lambda)$ $d \lambda$ from 0.28 to $1.0 \mu \mathrm{m}$ yields a cumulative absorption of only $3.2 \mathrm{~W} \mathrm{~m}^{-2}$. In contrast the integral of $P(\lambda)$ over the interval $1.0-4.0 \mu \mathrm{m}$ yields a cumulative absorption of $78.2 \mathrm{~W} \mathrm{~m}^{-2}$. For the optically thicker cumulonimbus cloud, integrating $P(\lambda)$ 
(A) CLEAN PRECIPITATING ANVIL

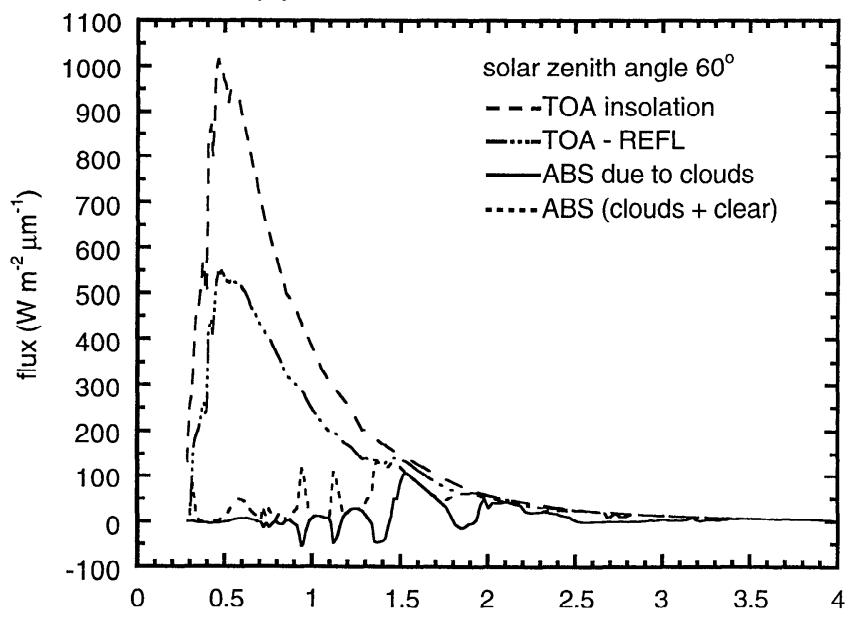

(C) DUSTY PRECIPITATING ANVIL

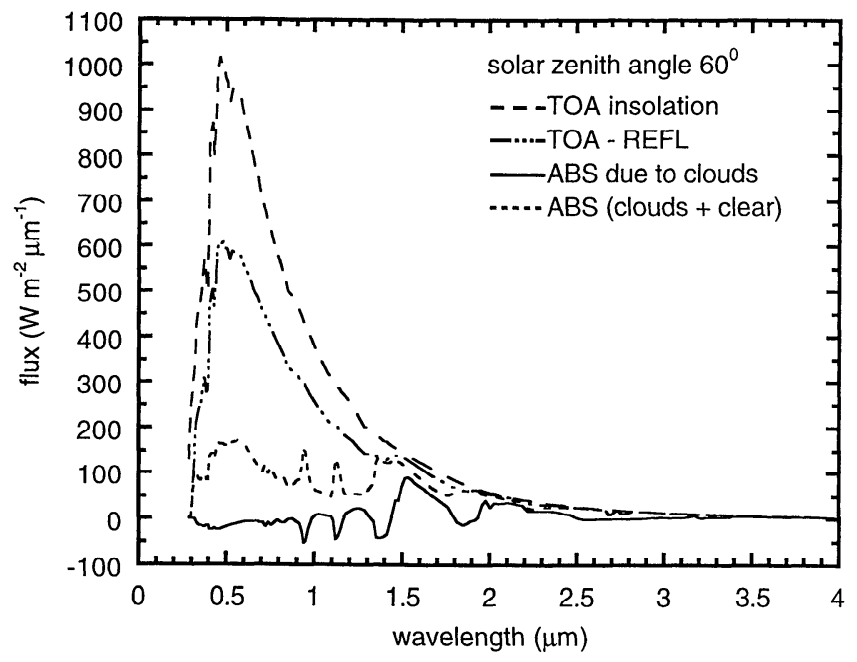

(B) CLEAN CUMULONIMBUS

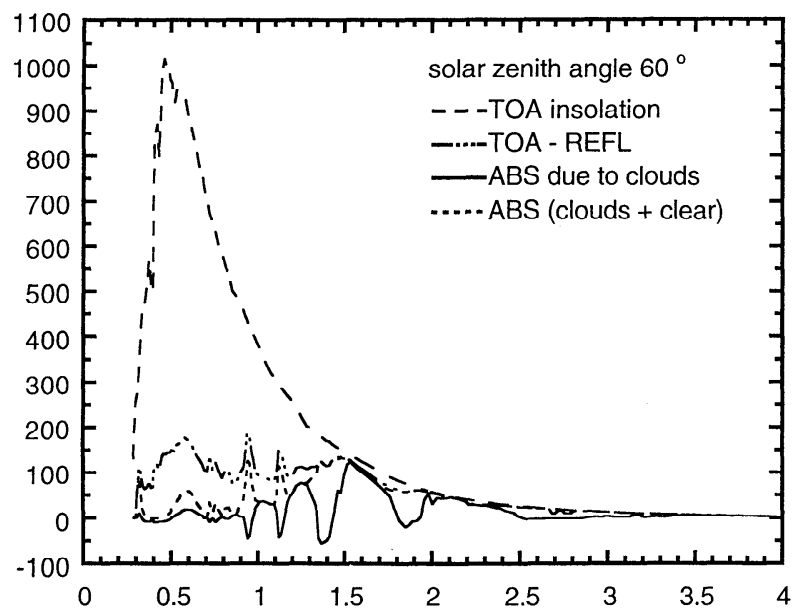

(D) DUSTY CUMULONIMBUS

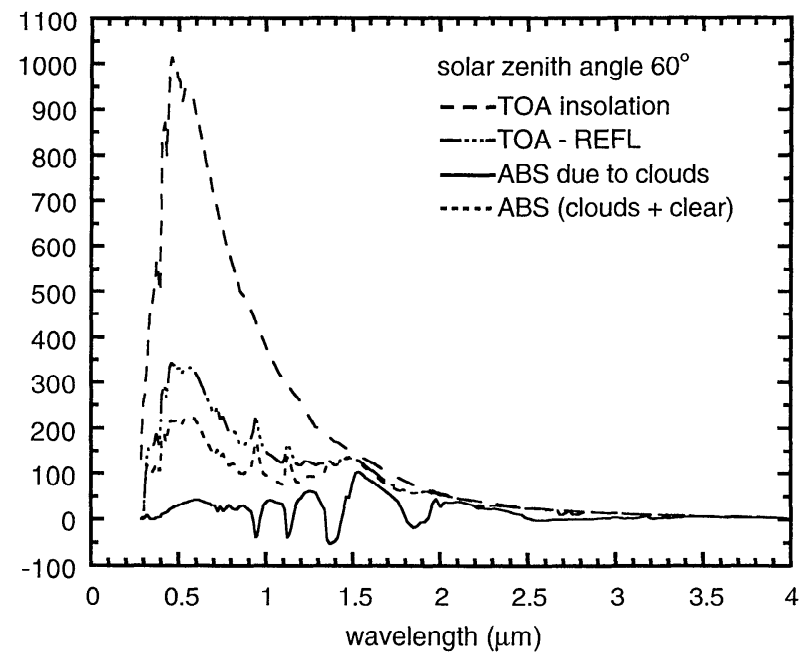

Figure 8. As in Figure 6 but under a solar zenith angle of $60^{\circ}$.

from 0.28 to $1.0 \mu \mathrm{m}$ yields a cumulative absorption of $17.0 \mathrm{~W}$ $\mathrm{m}^{-2}$, indicating a more noticeable multiple-scattering effect. The $1.0-$ to $4.0-\mu \mathrm{m}$ integral of $P(\lambda)$ for this cloud is $152.0 \mathrm{~W}$ $\mathrm{m}^{-2}$.

In Figures $7 \mathrm{a}$ and $7 \mathrm{~b}$, there are some wavelength intervals, corresponding to strong gaseous absorption features, where the quantity $P(\lambda)<0$. At these wavelengths the effect of the cloud is to reduce the atmospheric absorption taking place, relative to the clear sky case, by reflecting radiation back to space beforc it can cnter the absorbing column. In these wavelength intervals, $C_{s s}(\lambda) / C_{s t}(\lambda)<1$.

\section{Limitations of a Dusty Atmosphere Explanation}

We have shown that the ratio $C_{s s}(\lambda) / C_{s t}(\lambda)$ is much larger than unity in the near infrared, where the cloud singlescattering albedo is noticeably smaller than unity. In searching for an explanation for the empirical ratios $C_{s s} / C_{s t} \approx 1.5$, one possible approach is to examine if there is some atmospheric constituent that reduces the single-scattering albedo at visible wavelengths by a noticeable amount. Interstitial aerosol or dust particles entrained in the cloud would make such a reduction in the effective cloud single-scattering albedo and are a rea- sonable speculation. Our objective in including this apparently unrelated effect is simply to illustrate that interstitial aerosols, even the absorbing ones, do not lead to excess absorption. We repeated our radiative transfer calculations for the four cloud cases, for a model atmosphere that contained an aerosol layer well mixed in the troposphere and with a total $0.5-\mu \mathrm{m}$ optical depth of 0.3. By making the aerosol layer well mixed throughout the troposphere, we are introducing an extreme hypothesis that would be difficult to realize in nature, but we show that even in this extreme case of aerosol distributed throughout the troposphere, its effect on the cloud radiative properties cannot explain the excess cloud absorption.

The size distribution for natural, background continental aerosol was adapted from Seinfeld [1986], and aerosol refractive indices for use in the Mie calculations were taken from Nilsson [1979]. This aerosol content is retained in the clear sky reference calculations. For the optically thick cumulonimbus the addition of this aerosol layer is equivalent to reducing the single-scattering albedo at $0.5 \mu \mathrm{m}$ from 1.000 to 0.9942 . For the optically thin cirrus the reduction in $0.5-\mu \mathrm{m}$ singlescattering albedo is much larger (0.9989 to 0.6249) due to the larger ratio of aerosol optical depth to cirrus optical depth.

Curves for $S(\lambda), P(\lambda)$, and $P_{t}(\lambda)$ for the precipitating anvil 
CLEAN ATMOSPHERE
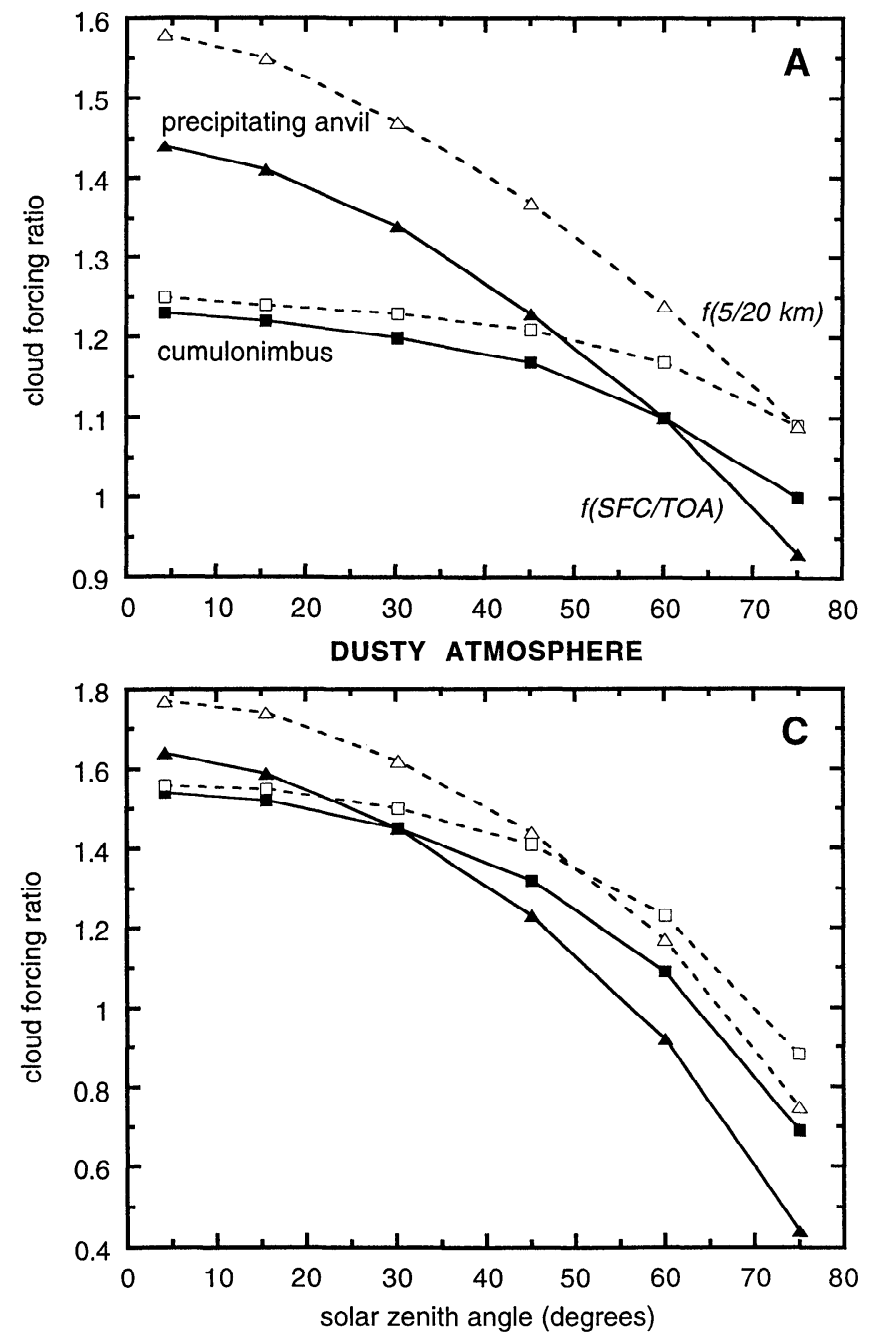

CLEAN ATMOSPHERE
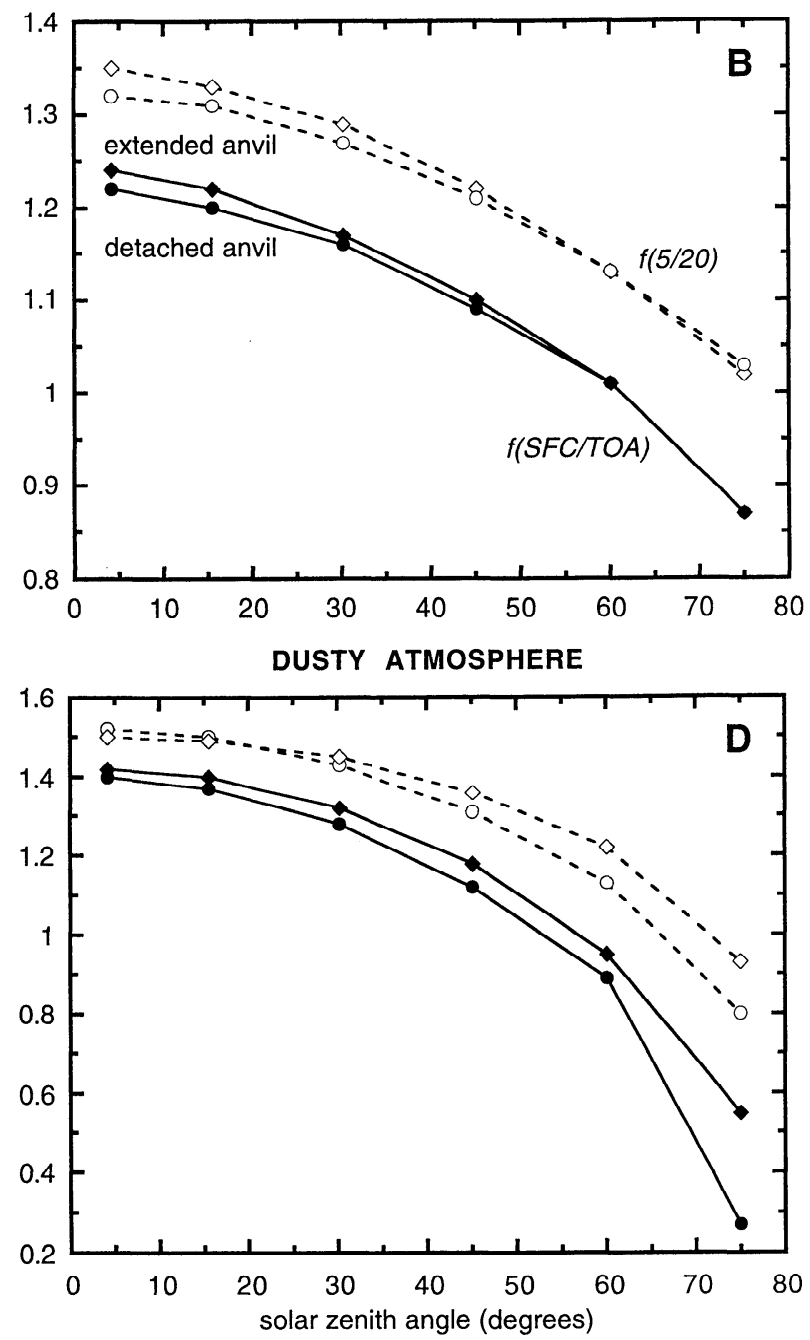

Figure 9. Solar zenith angle dependence in the cloud forcing ratio $f_{s}$ (surface/top of the atmosphere, solid curves) and $f_{s}^{*}(5 / 20 \mathrm{~km}$, dashed curves), for (a) the clean atmosphere, cumulonimbus (squares), and precipitating anvil (triangles); (b) the clean atmosphere, extended anvil (diamonds) and detached anvil (circles); (c) the dusty atmosphere, cumulonimbus (squares), and precipitating anvil (triangles); and (d) the dusty atmosphere, extended anvil (diamonds), and detached anvil (circles).

and cumulonimbus in this dusty atmosphere are shown in Figures $7 \mathrm{c}$ and $7 \mathrm{~d}$, respectively. For the cirrus cloud and wavelengths less than $1.0 \mu \mathrm{m}$, the addition of the aerosol increases the integrated shortwave cloud absorption effect, $P=\int P(\lambda)$ $d \lambda$, from 3.2 to $25.3 \mathrm{~W} \mathrm{~m}^{-2}$, while the integrated cloud absorption effect from 1.0 to $4.0 \mu \mathrm{m}$ decreases slightly from 78.2 to $76.7 \mathrm{~W} \mathrm{~m}^{-2}$. For the cirrus cloud the presence of the aerosol increases the integrated shortwave cloud absorption effect from 81.4 to $102.0 \mathrm{~W} \mathrm{~m}^{-2}$. The impact of aerosol is even more significant for the cumulonimbus (Figure 7d). For wavelengths less than $1.0 \mu \mathrm{m}$, the addition of the aerosol increases the integrated cloud absorption effect from 17.0 to $130.2 \mathrm{~W} \mathrm{~m}^{-2}$, and the cumulative cloud absorption effect from 1.0 to $4.0 \mu \mathrm{m}$ increases slightly from 152.0 to $153.4 \mathrm{~W} \mathrm{~m}^{-2}$. This constitutes an increase in the total shortwave cloud absorption effect from 169.0 to $283.6 \mathrm{~W} \mathrm{~m}^{-2}$.

The addition of the aerosol layer of Figures $7 \mathrm{c}$ and $7 \mathrm{~d}$ has a small impact on the cloud forcing ratio $f_{s}$ for the three types of cirrus clouds. For solar zenith angle $10^{\circ}$ the ratios $f_{s}$ are 1.53, $1.62,1.39$, and 1.41 for the CB, PA, EA, and DA, respectively. Although these ratios are slightly higher at near-overhead Sun for the dusty atmosphere, the additional absorption from the aerosol increases the dependence in $C_{s} / C_{t}$ upon solar zenith angle. Figures $8 \mathrm{a}-8 \mathrm{~d}$ show the quantities $S(\lambda), P(\lambda)$, and $P_{t}(\lambda)$ for the clean and dusty PA and CB, for a solar zenith

Table 1. Summary of the Cloud Forcing Ratios $f_{s}$ for the Various Cases Considered in This Study

\begin{tabular}{lcc}
\hline \multicolumn{1}{c}{ Case } & $f_{s}\left(\theta_{o}=10^{\circ}\right)$ & $\left\langle f_{s}\right\rangle$ \\
\hline CB & 1.23 & 1.18 \\
PA & 1.43 & 1.26 \\
EA & 1.23 & 1.12 \\
DA & 1.21 & 1.10 \\
Areal and diurnal average & 1.53 & 1.18 \\
CB with aerosol & 1.62 & 1.38 \\
PA with aerosol & 1.39 & 1.26 \\
EA with aerosol & 1.41 & 1.08 \\
DA with aerosol & & 1.20 \\
Areal and diurnal average, with aerosol & &
\end{tabular}

$\mathrm{CB}$, cumulonimbus; PA, precipitating anvil; EA, extended anvil; DA, detached anvil. 
angle of $60^{\circ}$. In the clean atmosphere cases the small wavelength intervals where $P(\lambda)$ is negative at small solar zenith angle (Figures 7a and $7 \mathrm{~b}$ ) show $P(\lambda)$ as more negative at large solar zenith angle (Figures $8 \mathrm{a}$ and $8 \mathrm{~b}$ ). For the dusty CB the excess visible absorption effect noticed in the near-overhead Sun calculation (Figure 7d) is almost all gone at large solar zenith angle (Figure 8d). For the dusty PA, $P(\lambda)$ is actually ncgative throughout most of the visible (Figurc 8c), signifying that the cloud's enhanced albedo at high solar zenith angle prevents significant visible radiation from penetrating deeper into the troposphere, where it would be absorbed in the clear sky case. For a solar zenith angle of $60^{\circ}$ the ratio $f_{s}$ is 1.10 for both the clean air PA and $\mathrm{CB}$ and 0.92 and 1.09 for the dusty $\mathrm{PA}$ and $\mathrm{CB}$, respectively.

The full solar zenith angle dependence in $f_{s}$ is shown for the four cloud types in the clean atmosphere in Figures $9 a$ and $9 b$ and for the four cloud types in the dusty atmosphere in Figures $9 \mathrm{c}$ and 9d. For all cloud types the solar zenith angle dependence in $f_{s}$ is larger in the dusty atmosphere, due to the albedo effect described above. The clear sky reference calculations were performed first taking into account the known solar zenith angle dependence in sea surface albedo and then with a strictly Lambertian sea surface. The difference between the two cases was negligible. Also shown in Figures 9a-9d are the ratios $f_{s}^{*}$ relevant to colocated aircraft measurements. These ratios show the same degree of solar zenith angle dependence, indicating that this dependence is intrinsic to the cloud itself and not due in any large part to intervening atmosphere between the cloud and the satellite/surface radiometers. The diurnally average values $\left\langle f_{s}\right\rangle$ for the dusty atmosphere are 1.38, $1.26,1.08$, and 1.19 for the CB, PA, EA, and DA, respectively. This result for the $\mathrm{CB}$ is the only case in this study where the plane-parallel modeling approaches the recent experimental results and, apparently, results from the many scattering events that occur in a cloud of optical depth greater than 50, where the single-scattering albedo at visible wavelengths has been reduced below unity. However, the $\mathrm{CB}$ turret makes is only $5 \%$ of the area in the anvil system. If we apply (5) to the dusty atmosphere calculations, we find that the area-averaged and diurnally averaged cloud forcing ratio $\left\langle f_{s}\right\rangle=1.20$.

\section{Summary and Conclusions}

Using altitude-dependent tropical cloud microphysics, with pure water and pure ice, in a one-dimensional radiative transfer model, we can obtain cloud forcing ratios of nearly 1.5 under near-overhead Sun. This result is duc to both particle size and phase. For a given cloud liquid or ice water content, larger drops absorb more solar radiation because absorption depends upon the volume of the drop, while scattering depends upon the cross-sectional area. Wiscombe et al. [1984] have shown the importance of including large liquid water drops in a complete radiative transfer formulation. Here we have shown that the inclusion of large ice particles can make the instantaneous midday cloud forcing ratios approach those of the recent empirical studies. At all near-infrared wavelengths the ice phase is important simply because ice particles are generally much larger than water droplets in clouds (Figure 2 ). In the $1.6-\mu \mathrm{m}$ window the ice phase itself increases the absorption. This is ultimately related, through Mie theory, to the complex refractive index which at $1.6 \mu \mathrm{m}$ is 4 times larger for ice than for water [Hale and Query, 1973; Warren, 1984]. These absorption effects are somewhat reduced at large cloud optical depth. As clouds become optically thick, the albedo increases so much that the decrease in insolation overwhelms the increasc in ice absorption; hence we sec smaller ratios $f_{s}$ over cumulonimbus clouds.

Despite our success in reproducing $C_{s s} / C_{s t} \approx 1.5$ for nearly overhead Sun, the empirical studies [Cess et al., 1995; Pilewskie and Valero, 1995; Ramanathan et al., 1995] are based on diurnal avcrages $\left\langle f_{s}\right\rangle=\left\langle C_{s s}\right\rangle /\left\langle C_{s t}\right\rangle$. Our model $\left\langle f_{s}\right\rangle$ gencrally remains around 1.2, due to the cloud albedo effect increasing with solar zenith angle (Table 1). This may be a pathological flaw of plane parallel cloud models. The albedo of a cloud with realistic cloud top orography and shapes (with Sun shining on the sides as well) may not exhibit the same strong sensitivity to zenith angle. If the albedo of the cloud does not increase with zenith angle (due to the three-dimensional effects), but the absorption does (due to the slant path which does not depend on the cloud shape or size), then the decrease in $f_{s}$ (with increasing zenith angle) would be much weaker than the present results. Adding dust or aerosol to the atmosphere does not increase $\left\langle f_{s}\right\rangle$, because in the presence of the dust or aerosol the solar zenith angle dependence in $C_{s s} / C_{s t}$ becomes even stronger.

In addition to the dusty atmosphere calculation, we tried another set of computations to simulate the presence of trade cumulus below the cirrus anvils. This was approximated by adding a liquid water scattering layer of (visible wavelength) optical depth 3, having the droplet size distribution of the $6-\mathrm{km}$ layer of the $\mathrm{CB}$. We found that the solar zenith angle dependence in $f_{s}$ lessened by a few percent, but not by enough to dramatically change the diurnal average. One remaining possibility is that there may be a chemical composition of the cloud particles themselves that makes their single-scattering albedo significantly less than unity at visible wavelengths. The absorption effect of such impure water droplets or ice particles would have to be strong enough to overcome the solar zenith angle dependence in the cloud albedo effect.

In this study we have also reported a set of colocated aircraft measurements that yield larger cloud forcing ratios than can be explained by a plane-parallel model using our very large ice particle simulations and a small solar zenith angle. This study has therefore served to articulate an important limitation with planc-parallel radiative transfer modeling, that with pure water cloud microphysics; modeled cloud absorption is generally much smaller than that observed in the field or from space.

Acknowledgments. This study was supported by U.S. Department of Encrgy DOE DE-FG03-91ER61198, by National Science Foundation NSF ATM 94 05024, and by National Science Foundation NSF ATM 92 23467. This report is National Science Foundation Center for Clouds, Chemistry, and Climate contribution 131.

\section{References}

Carrier, L. W., G. A. Cato, and K. J. von Essen, The backscattering and extinction of visible and infrared radiation by selected major cloud models, Appl. Opt., 6, 1209-1216, 1967.

Cess, R. D., et al., Absorption of solar radiation by clouds: Observations versus models, Science, 267, 496-499, 1995.

Chen, J. P., and D. Lamb, Simulation of cloud microphysical and chemical processes using a multicomponent framework, I, Description of the microphysical model, J. Atmos. Sci., 51, 2613-1630, 1994.

Frederick, J. E., and D. Lubin, The budget of biologically active ultraviolet radiation in the Earth-atmosphere, J. Geophys. Res., 93, 3825$3832,1988$. 
Hale, G. M., and M. R. Query, Optical constants of water in the 200-nm to 200-mm wavelength region, Appl. Opt., 12, 555-563, 1973.

Kiehl, J. T., and B. P. Briegleb, The relative roles of sulfate aerosols and greenhouse gases in climate forcing, Science, 260, 311-314, 1993.

Knollenberg, R. G., K. Kelly, and J. C. Wilson, Measurements of high number densities of ice crystals in the tops of tropical cumulonimbus, J. Geophys. Res., 98, 8639-8664, 1993.

Laing, A. G., and M. Fritsch, Mesoscale convective complexes over the Indian monsoon region, J. Clim., 6, 911-919, 1993.

Li, Z., H. W. Barker, and L. Moreau, The variable effect of clouds on atmospheric absorption of solar radiation, Nature, 376, 486-490, 1995.

Liou, K. N., Radiation and Cloud Processes in the Atmosphere, 487 pp., Oxford Univ. Press, New York, 1992.

I ubin, D., The role of the tropical super greenhouse effect in heating the ocean surface, Science, 265, 224-227, 1994.

McFarquhar, G. M., and A. J. Heymsfield, Microphysical characteristics of threc anvils sampled during the Central Equatorial Pacific Experiment (CEPEX), J. Atmos. Sci., in press, 1996.

Nilsson, B., Meteorological influence on aerosol extinction in the $0.2-$ 40-mm wavelength range, Appl. Opt., 18, 3457-3473, 1979.

Pilewskie, P., and F. P. J. Valero, Direct observation of excess solar absorption by clouds, Science, 267, 1626-1629, 1995.

Ramanathan, V., B. Subasilar, G. Zhang, W. Conant, R. D. Cess, J. Kiehl, H. Grassl, and L. Shi, Warm pool heat budget and shortwave cloud forcing: A missing physics?, Science, 267, 499-503, 1995.

Seinfeld, J. H., Atmospheric Chemistry and Physics of Air Pollution, 738 pp., John Wylie, New York, 1986.

Slingo, A., A GCM parameterization for the shortwave radiative properties of water clouds, J. Atmos. Sci., 46, 1419-1427, 1989.

Stamnes, K., S.-C. Tsay, W. Wiscombe, and K. Jayaweera, Numerically stable algorithm for discrete-ordinate-method radiative transfer in multiple scattering and emitting layered media, Appl. Opt., 27, 25022508, 1988.
Stephens, G. L., and S.-C. Tsay, On the cloud absorption anomaly, Q.J. R. Meteorol. Soc., 116, 671-704, 1990.

Warren, S. G., Optical constants of ice from the ultraviolet to the microwave, Appl. Opt., 23, 1206-1223, 1984.

Webster, P., and R. Lukas, TOGA COARE: The coupled oceanatmosphere response experiment, Bull. Am. Meteorol. Soc., 73, 1377-1416, 1992.

Whitby, K. T., The physical characteristics of sulfur aerosols, Atmos. Environ., 12, 2663-2681, 1978.

Wiscombe, W. J., Improved Mie scattering algorithms, Appl. Opt., 19, 1505-1509, 1980.

Wiscombe, W. J., and J. W. Evans, Exponential sum fitting of radiative transmission functions, J. Comput. Phys., 24, 416-444, 1977.

Wiscombe, W. J., R. M. Welch, and W. D. Hall, The effects of very large drops on cloud absorption, I, Parcel models, J. Atmos. Sci., 41, $1336-1355,1984$.

Wisner, C., II. D. Orville, and C. Myers, A numcrical model of a hail-bearing cloud, J. Atmos. Sci., 29, 1160-1180, 1972.

J.-P. Chen, Department of Atmospheric Sciences, National Taiwan University, Taipci, Taiwan.

D. Lubin (corresponding author), and V. Ramanathan, Center for Clouds, Chemistry, and Climate, Scripps Institution of Oceanography, University of California, San Diego, California 92093.

P. Pilewskie, NASA Ames Research Center, Moffett Field, California 94035.

F. P. J. Valero, Atmospheric Research Laboratory, Scripps Institution of Oceanography, University of California, San Diego, La Jolla, California 92093.

(Received Fcbruary 13, 1995; revised March 22, 1996; accepted March 22, 1996. . 